\title{
Existence and Learning of Teaching Network for CRNN
}

\author{
Neeraj Sahu \\ Department of Mathematics and Applied Science \\ Jiwaji University \\ Gwalior (M. P.), India
}

\author{
Avanish Kumar \\ Department of Mathematical, Sciences and Computer \\ Applications, Bundelkhand University \\ Jhansi (U. P.), India
}

\begin{abstract}
Existence and Learning of Teaching Network for Complex Recurrent Neural Network (CRNN) has been discussed in this piece of research. Issues related to the quaternionic neural network have been taken into consideration. In this paper by considering the special class of CRNN for which existence of attractive periodic solution in teaching network has been obtained and theoretical results has been proved, limit cycle, existence and uniqueness have also been discussed. This work has very much significant for several real world applications.
\end{abstract}

\section{Keywords}

Complex Recurrent Neural Network; Limit Cycle; Learning Systems; Periodic Orbits.

\section{INTRODUCTION}

The properties and presentation of complex valued neural networks have been widely discover in the cases of single neuron model multilayered perceptrons and recurrent neural networks. There are numerous function of quaternion to the neural networks and quaternion is a four dimensional hyper complex number system. The computational ability of a single quaternary neurons is discussed by[1].The multilayered with quaternionic neurons and their learning algorithms have been discussed [2]-[4].The several practical problem to the time series predictions, rigid body control[5],Color image compression [3] and extraction of color information from night vision image[6], of the quaternionic multilayered perceptrons. The existence condition of energy function in Hopfield type quaternionic neural network has been clarified in the case of continuous value of neuron states and continuous time [7].

In this paper we explore a particular class of Complex Recurrent Neural Network (CRNN).We have taken three nodes case of monotone dynamical system theory to represent a well defined set of structure for that every orbit of CRNN is asymptotic to a period orbit. This class of CRNN is shown to a group of stable limit cycle.

\section{DESCRIPTION OF PROBLEM}

Consider the following neural network in which,

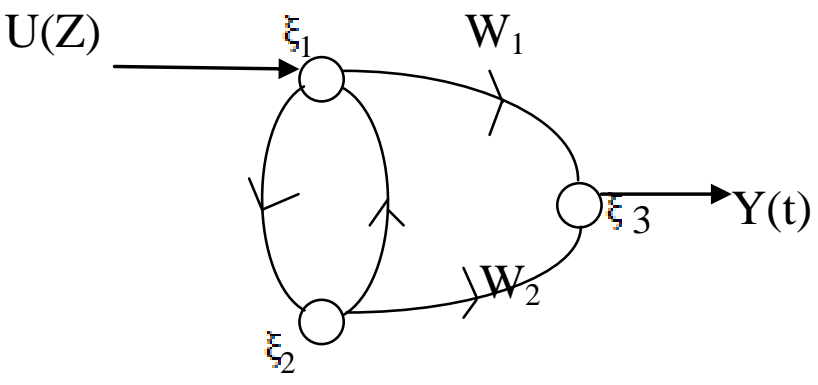

In this figure we consider $U(Z)$ is the input and $Y(Z)$ is the output. This neural network is described properly by the coordination of differential equations involving complex variable.

$$
\dot{\xi}_{1}(\mathrm{Z})=-\xi_{1}(\mathrm{Z})+\xi_{2}(\mathrm{Z})
$$

$\xi_{2}(Z)=-\xi_{2}(Z)+\xi_{1}(Z)$

$\xi_{a}(\mathrm{Z})=-\xi_{a}(\mathrm{Z})+\mathrm{W}_{1} \xi_{1}(\mathrm{Z})+\mathrm{W}_{2} \xi_{2}(\mathrm{Z})$

$$
\mathrm{Y}(\mathrm{Z})=\xi_{\mathrm{a}}(\mathrm{Z})
$$

where $\bar{\xi}(\mathrm{Z})=\frac{\mathrm{d} q}{\mathrm{dz}}, \mathrm{Z}=\mathrm{U}+\mathrm{iV}$ and $\xi(\mathrm{Z}) \in \mathrm{R}_{\mathrm{c}}{ }^{\mathrm{n}}, \mathrm{n}=1,2,3$ is this state $\mathrm{W}_{\mathrm{i}}$ $\equiv \mathrm{R}_{\mathrm{c}}{ }^{\mathrm{n}}, \mathrm{i}=1,2$ are the network parameter of weights.

At $\xi(Z)=0$ combined with bounded of the solution forces the system to generate a limit cycle. The freedom in choosing $W_{1}$ and $W_{2}$ in the system (1) allows us to determine the position of the pole.

Let

$$
A=\left[\begin{array}{ccc}
-1 & 1 & 0 \\
1 & -1 & 0 \\
W_{1} & W_{2} & -1
\end{array}\right]
$$

The roots of the characteristic polynomial is $A-\lambda I=0$ given by.

$$
(-1-\lambda)\left[(1+\lambda)^{2}-1\right]=0
$$

Let

$$
f(\lambda):=\left[\lambda^{3}+3 \lambda^{2}+2 \lambda\right]=0
$$


Differentiating (2),

$f^{\prime}(\lambda):=3 \lambda^{2}+6 \lambda+2=0$

The roots of (3) are given by

$$
h_{1}=-1+\frac{1}{\sqrt{2}}, \quad h_{1}=-1-\frac{1}{\sqrt{2}}
$$

A necessary and sufficient condition for $f(\lambda)$ to have a pair of complex conjugate roots is that

$\mathrm{f}\left(\lambda_{1}\right) \mathrm{f}\left(\lambda_{2}\right)>0$, according to Ruiz, Owens and Townley [8] from (2),we obtain,

$$
\mathrm{f}\left(\lambda_{1}\right) \mathrm{f}\left(\lambda_{2}\right)=\frac{2}{\mathrm{a}} \quad>0
$$

Equation (5) has a limit cycle at the origin.

\section{EXISTENCE OF ATTRACTIVE PERIODIC SOLUTION IN THE TEACHING NETWORK}

The teaching network with state $\mathrm{X}(\mathrm{Z})$ : $=\left(\mathrm{X}_{1}(\mathrm{Z}), \mathrm{X}_{2}(\mathrm{Z}), \mathrm{X}_{3}(\mathrm{Z})\right)^{\mathrm{T}}$ $\equiv \mathrm{R}_{\mathrm{c}}{ }^{\mathrm{n}}$ (Complex Recurrent Neural Network) and $\mathrm{X}(0):=\mathrm{X}_{0} \equiv \mathrm{R}_{\mathrm{c}}{ }^{\mathrm{n}}$ has similar structure to (1) but the corresponding weight vector $\mathrm{W}^{*}:=\left(\mathrm{W}_{1} * \mathrm{~W}_{2}{ }^{*}\right)^{\mathrm{T}}$ is fixed and the loop from $\mathrm{Y}(\mathrm{Z})$ to $\mathrm{U}(\mathrm{Z})$ is closed with unity feed back.

The three node version of teaching network represented by (1)

$$
\begin{aligned}
& \dot{\mathrm{X}}_{1}(\mathrm{Z})=-\mathrm{X}_{1}(\mathrm{Z})+\mathrm{X}_{2}(\mathrm{Z}) \\
& \dot{\mathrm{X}}_{2}(\mathrm{Z})=-\mathrm{X}_{2}(\mathrm{Z})+\mathrm{X}_{1}(\mathrm{Z}) \\
& \dot{\mathrm{X}}_{\mathrm{a}}(\mathrm{Z})=-\mathrm{X}_{\mathrm{a}}(\mathrm{Z})+\mathrm{W}_{1}^{*} \mathrm{X}_{1}(\mathrm{Z})+\mathrm{W}_{2}^{*} \mathrm{X}_{2}(\mathrm{Z})
\end{aligned}
$$

To prove range of weights that each trajectory of (6) which does not tends to equilibrium $\mathrm{X}=0$, tends to a periodic orbit. It is monotone dynamical system and by using the techniques from monotone dynamical system theory, we discussed competitive system results for the proposition [9].

Let the system $\xi(\mathrm{Z})=\mathrm{f}(\xi), \xi(0)=\xi_{0} \equiv \mathrm{R}_{\mathrm{c}}{ }^{3}$, with $\mathrm{f}$ continuously differentiable on an open set

$\mathrm{V} \subset \mathrm{R}_{\mathrm{c}}{ }^{3}$ be spirited on $\mathrm{V}$ that contains a unique equilibrium point $\xi_{\mathrm{E}}$, which is hyperbolic. Let $\mathrm{W}^{\mathrm{s}}\left(\xi_{\mathrm{e}}\right)$ the stable manifold at $\xi_{\mathrm{e}}$, is tangential at $\xi_{\mathrm{e}}$ to a non negative vector and one dimensional.
If $\xi_{0} \notin \mathrm{W}^{\mathrm{s}}\left(\xi_{\mathrm{e}}\right)$ and the positive semi orbit $v^{+}$ $\left(\xi_{0}\right):=\{\xi(Z): Z \geq 0\}$ have complete closure in $\gamma$ then the $\omega$-limit set, $\omega\left(\xi_{0}\right)$ of $\xi_{0}$ is a non trivial periodic orbit.

These types of results sometimes referred to as a Poincare Bendixson theorem for three dimensional systems except in the special case of cyclic systems that does not generalize to higher dimensions [10]. If the periodic orbits does not provide us with any information concerning the uniqueness and stability by the monotone system theory. These types of tool for establishing the existence of attractive periodic orbits in the teaching network (6).

\section{LEARNING THE OUTPUT FROM THE TEACHING NETWORK}

In this system we create weight adaption algorithms which enable the learning complex recurrent neural network to train the output of the teaching network. The learning CRNN converge exponentially to the stable $\mathrm{X}(\mathrm{Z})$ and fixed weight vector. $\mathrm{W}^{*}$ of the teaching network.

THEOREM 1 The three node teaching network (1) and its corresponding three node learning CRNN is,

$$
\begin{gathered}
\xi_{1}(\mathrm{Z})=-\xi_{1}(\mathrm{Z})+\xi_{2}(\mathrm{Z}) \\
\xi_{2}(\mathrm{Z})=-\xi_{2}(\mathrm{Z})+\mathrm{U}(\mathrm{Z}) \\
\xi_{\mathrm{a}}(\mathrm{Z})=-\xi_{\mathrm{a}}(\mathrm{Z})+\mathrm{W}_{1} \xi_{1}(\mathrm{Z})+\mathrm{W}_{2} \xi_{2}(\mathrm{Z}) \\
\mathrm{U}(\mathrm{Z})=\xi_{\mathrm{a}}(\mathrm{Z})
\end{gathered}
$$

Define the weight adaption algorithm by

$$
\begin{aligned}
& \tilde{W}_{1}(\mathrm{Z})=-\left(\xi_{\mathrm{a}}(\mathrm{Z})-\mathrm{X}_{\mathrm{a}}(\mathrm{Z})\right) \xi_{1}(\mathrm{Z}) \\
& \tilde{W}_{2}(\mathrm{Z})=-\left(\xi_{\mathrm{a}}(\mathrm{Z})-\mathrm{X}_{\mathrm{a}}(\mathrm{Z})\right) \xi_{\mathrm{a}}(\mathrm{Z})
\end{aligned}
$$

Then for arbitrary initial condition $\mathrm{X}(0), \mathrm{Z}(0) \in \mathrm{R}_{\mathrm{c}}{ }^{3}$ and $\mathrm{W}(0)$ $E \mathrm{R}_{\mathrm{c}}{ }^{3}$ the closed loop system (6)-(9)has a unique solution defined on $[0, \infty)$ Furthermore, if $\mathrm{X}(0)$ is a non trivial periodic solution of the (6) then there exist $\mathrm{M}, \lambda>0$ independent of $\mathrm{Z}(0) \equiv \mathrm{R}_{\mathrm{c}}{ }^{3}$ and $\mathrm{W}(0) \in \mathrm{R}_{\mathrm{c}}{ }^{3}$ so that

$$
\left\|\left(\begin{array}{l}
\xi(\mathrm{z})-\mathrm{X}(\mathrm{Z}) \\
\mathrm{W}(\mathrm{z})-\mathrm{W}^{*}
\end{array}\right)\right\| \leq \mathrm{M} e^{-\mathrm{z}(\mathrm{L})}\left\|\left(\begin{array}{l}
\xi(0)-\mathrm{X}(0) \\
\mathrm{W}(0)-\mathrm{w}^{*}
\end{array}\right)\right\|,
$$


for all $\mathrm{Z}>0$

PROF Existence and uniqueness of solution on $[0, \infty)$ is definite because the right hand side of the closed loop system (6)-(10)is continuous and affine linearly bounded.

$$
\begin{aligned}
& \text { Let } \dot{e}_{1}(\mathrm{Z})=-\mathrm{e}_{1}(\mathrm{Z})+\beta_{2}(\mathrm{Z}) \\
& \hat{\mathrm{e}}_{2}(\mathrm{Z})=-\mathrm{e}_{2}(\mathrm{Z}) \\
& \tilde{e}_{a}(Z)=-e_{a}(Z)+W_{1}(Z) \xi_{1}(Z)+W_{2}(Z) \xi_{2}(Z)+w_{1}^{*} \beta_{1}(Z)+
\end{aligned}
$$$$
\mathrm{W}_{2}^{*} \beta_{2}(\mathrm{Z})
$$

Where for $\mathrm{i}=1$ or $2, \beta_{\mathrm{i}}(\mathrm{Z}) \mathrm{x}=\beta_{\mathrm{i}}(\mathrm{Z})-\mathrm{X}_{\mathrm{i}}(\mathrm{Z})$ and $\widetilde{\mathrm{W}}_{\mathrm{x}}:=$ $W_{i}(Z)-W_{i}^{*}$ clearly from (11)

$$
e_{2}(Z)=e^{-z} e_{2}(0) \quad \text { for all } Z \geq 0
$$

Since a $\rightarrow \xi($ a) has a global Lipschitz constant equal to one we have that

$\left|\beta_{\mathrm{i}}(\mathrm{Z})\right| \leq\left|\mathrm{e}_{\mathrm{i}}(\mathrm{Z})\right|_{\text {, }}$ for all $\mathrm{Z} \geq 0$ and $\mathrm{i}=1,2$

It follows using variation of constants in the first equation in (10) and then taking estimates that

$$
\begin{aligned}
\left|\mathrm{e}_{1}(\mathrm{z})\right| & \leq \mathrm{e}^{-\mathrm{z}}\left|\mathrm{e}_{1}(0)\right|+\int_{0}^{z} \mathrm{e}^{-(\mathrm{z}-S)}\left|\beta_{2}(S)\right| d S \\
& \leq \mathrm{e}^{-\mathrm{z}}\left|\mathrm{e}_{1}(0)\right|+\int_{0}^{z} \mathrm{e}^{-(\mathrm{Z}-\mathrm{S})}\left|\mathrm{e}_{2}(\mathrm{~S})\right| \mathrm{dS} \\
& \leq \mathrm{e}^{-\mathrm{z}}\left|\mathrm{e}_{1}(0)\right|+\mathrm{e}^{-\mathrm{z}} \mathrm{z}\left|\mathrm{e}_{2}(0)\right| \\
& \leq \mathrm{e}^{-\mathrm{z}}\left|\mathrm{e}_{1}(0)\right|+2 \mathrm{e}^{-\mathrm{z} / 2} \mathrm{e}^{-1}\left|\mathrm{e}_{2}(0)\right|
\end{aligned}
$$

Hence there exists $M_{1}, \lambda_{1}>0$ such that

$$
\left|\mathrm{e}_{\mathrm{i}}(\mathrm{Z})\right| \leq \mathrm{M}_{1} \mathrm{e}^{-\mathrm{Z}_{2} \mathrm{z}}\|\mathrm{e}(0)\| \text { for all } \mathrm{Z} \geq 0 \text { and } \mathrm{i}=1,2
$$

Now we have to show that $\eta(Z):=\left(\mathrm{e}_{a}(\mathrm{Z}), \widetilde{\mathrm{W}}_{1}(\mathrm{Z}), \widetilde{\mathrm{W}}_{2}(\mathrm{Z})\right)^{\mathrm{T}}$ decays to zero exponentially. Certainly we will show that the weights are bounded now differentiating.

$$
\mathrm{V}(\mathrm{Z})=\frac{1}{2}\|\eta(\mathrm{Z})\|^{2}
$$

The length of solution and using (13) and (14) we obtain all $\mathrm{Z} \geq 0$ that

$$
\begin{aligned}
\dot{V}(Z) & =-\mathrm{e}_{a}^{2}(Z)+\mathrm{e}_{a}(Z)\left(W_{1}^{*} \beta_{1}(Z)+W_{2}^{*} \beta_{2}(Z)\right) \\
& \leq-e_{a}^{2}(Z)+\frac{1}{2}\left(\left|w_{1}^{*}\right|+\left|W_{1}^{*}\right|\right)^{2} M_{1}{ }^{2} e^{-2 z_{1} z}
\end{aligned}
$$

Integrating (15) from zero to $\mathrm{Z}$ gives

$$
\begin{aligned}
& \mathrm{V}(\mathrm{Z})=\|\eta(\mathrm{Z})\|^{2} \leq \mathrm{V}(\mathrm{O})-\frac{1}{2} \int_{0}^{\mathrm{z}} \mathrm{e}_{2}{ }^{2}(\mathrm{~S}) \mathrm{dS}+ \\
& \frac{1}{2} \int_{0}^{\infty}\left(\left|\mathrm{w}_{1}^{*}\right|+\left|\mathrm{w}_{1}^{*}\right|\right)^{2} \mathrm{M}_{1}{ }^{2} \mathrm{e}^{-2 \mathrm{Z}_{1} \mathrm{~S}} \mathrm{dS}<\infty
\end{aligned}
$$

It follows from (16) that $\eta($.$) and, in particular W (.) is bounded.$ The differential equation which illustrate evolution of $\eta(x)$ this can be written as follows

$\tilde{\eta}(Z)=A Z) \eta(Z)+P(Z) \eta(Z)+D(Z)$

$$
\begin{aligned}
& A(Z):=\left(\begin{array}{cc}
-1 & B(Z)^{\mathrm{T}} \\
-B(Z) & 0
\end{array}\right) \\
& P(Z):=\left(\begin{array}{ccc}
0 & 0 & 0 \\
\beta_{1}(Z) & 0 & 0 \\
-\beta_{2}(Z) & 0 & 0
\end{array}\right)
\end{aligned}
$$

$D(Z):=\left(\left[W_{1}(Z) \beta_{1}(Z)+W_{2}(Z) \beta_{2}(Z)\right], 0_{2} 0\right)^{\mathbb{I}}$ and $B($.$) is given$ by $\mathrm{B}(\mathrm{Z}):=\left(\xi_{1}(\mathrm{Z}){ }_{s} \xi_{2}(\mathrm{Z})\right)^{\mathrm{T}}$ and $\mathrm{P}(\mathrm{Z}), \mathrm{D}(\mathrm{Z})$ which we consider as perturbation term in (17)decay to zero exponentially, in analyzing (17). We consider the composed homogenous system

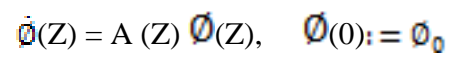

With $\emptyset_{(\mathrm{Z})} \equiv \mathrm{R}_{\mathrm{c}}{ }^{3}$. Since $\mathrm{B}(\mathrm{*})$ satisfies the persistency of excitation condition Lemma 3.6 in [11] it also follows Corollary 2.3 in [12] that the system given by (18) is equally exponentially stable. Now, using the fact that $\lim _{t \rightarrow \infty}\|\mathbb{P}(Z)\|=0$, it follows from normal perturbation results $[13, \mathrm{p} .134]$ that for the transition matrix $\psi(.,$. of

$$
\tilde{v}(\mathrm{Z})=(\mathrm{A}(\mathrm{Z})+\mathrm{P}(\mathrm{Z})) v(\mathrm{Z})
$$

There exists $\mathrm{M}_{2}, \lambda_{2}>0$ so that

$$
\|\Psi(\mathrm{t}, \mathrm{s})\| \leq \mathrm{M}_{2} \mathrm{e}^{-2.2(\mathrm{z}-\mathrm{s})}
$$

For all $\mathrm{Z} \geq \mathrm{S}$ and $\mathrm{S} \geq 0$ using variation of constants in (17) and estimating using (19) gives for all $\mathrm{Z} \geq 0$

$\|\eta(\mathrm{Z})\| \leq \mathrm{M}_{2} \mathrm{e}^{-\mathrm{z}_{2} \mathrm{z}} \eta(0)+\int_{0}^{\mathrm{Z}} \mathrm{M}_{2} \mathrm{e}^{-\mathrm{z}_{2}(\mathrm{Z}-\mathrm{S})}\|\mathrm{D}(\mathrm{S})\| \mathrm{dS}$

Now using the boundness of $\mathrm{W}($.$) and exponential decay to zero of$ $\beta_{1}(x)$ and $\beta_{2}(0)$ gives by (13) and (14) we have that $\|D(Z)\|$ converge to zero exponentially as t tends to $\infty$. It then follows that there exists $\mathrm{M}, \lambda>0$ so that (10) holds. 


\section{CONCLUSION}

In this paper we have shown the results from monotone dynamical system theory for three nodes CRNN with fixed weights of the teaching network that provides periodic solution. The inspiration behind the need for the teaching network to have periodic solutions occurs from the fact that learning usually needs repetition. Here we have used the periodic output of the teaching network as a teaching indication to be educated by a three node learning CRNN. This piece of research concludes the following results:

(i) The limit cycle proved for the origin.

(ii) Established the Existence of attractive periodic solution in the teaching network.

(iii) Learning the output from the teaching network for CRNN established.

The research work discussed in this paper has many applications in real world. It is helpful for designing and setting such network.

\section{REFERENCES}

[1] T. Nitta, "A solution to the 4-bit parity problem with a single Quaternary Neuron," Neural information processing - Leters and Reviews, vol.5 no.2, pp.33-39, 2004.

[2] P. Arena, L. Fortuna, G. Muscato, and M. Xibilia, " Multilayer perceptrons to approximate Quaternion valued functions," Neural Network vol.10,no.2,pp.335-342,1997.

[3] N. Matsui, T. Isokawa, H. Kusamichi, F. Peper and H. Nishimura, "Quaternion Neural Network with Geometrical Operation," Journal of Intelligent \& Fuzzy System,vol.15, no.3-4,pp. 149-164,2004.

[4] S. Buchholz and G. Sommer, "Quaternionic spinor MLP," in $8^{\text {th }}$ European Symposium on Artificial Neural Network (ESANN 2000),2000, pp.377-382.
[5] P. Arena, L. Fortuna, G. Muscato, and M.G. Xibilia, "Neural Networks in Multidimensional Domains," Ser. Lecture Notes in computer Science. Springer -Verlag,1998, vol.234.

[6] H. Kusamichi, T. Isokawa, N. Matsui,Y.Ogawa, and K.Maeda , "A New scheme for Color Night, Vision by Quaternion Neural Network," In Proceeding of the $2^{\text {nd }}$ International Conference on Autonomous Robots and Agents (ICARA 2004), 2004, pp.101-106.

[7] M.Yoshida, Y.Kuroe and T.Mori, " Models of hopfields-type Quaternion Neural Networks and their energy function," International Journal of Neural System, vol.15.no: 1-2, pp.129-135,2005.

[8] A. Ruiz, D. H.Owens, and S.Townley "Existence, learning, and replication of periodic motions in recurrent neural network," IEEE Trans. Neural Network. Vol. 9. no 4, pp 651- 661. Jul.1998.

[9] ----,Monotone Dynamical System. Providence, RI: Amer.Math.Soc., 1995.

[10] J. Mallet-Paret and H. Smith, "The Poincare-Bendixson theorem for monotone cyclic feedback system with delay, "J. Differential Equation, vol.2, pp.376-421,1990.

[11] S.Townley, A. Iichmann, M. G.WeiB, W. Mcclements, A. Ruiz, D. H. Owens, \& D. pretzel-Wolters, "Existences and learning of oscillations in recurrent neural networks. IEEE Trans. Neural Network"., vol. 11, no. 1, pp. 205-214. Jan. 2000.

[12] K.S.Narendra A.Annaswamy, Stable Adaptive System. Engelewood Cliffs, N.J:Prentice- Hall,1987.

[13] W. J. Rugh, "Linear system theory," Englewood cliffs NJ: Prentice-Hall 1996. 